\title{
DIVERSITY IN BODY SIZE AND FEEDING MORPHOLOGY WITHIN PAST AND PRESENT VULTURE ASSEMBLAGES ${ }^{1}$
}

\author{
FRITZ HERTEL \\ Department of Biology, University of California, Los Angeles, California 90024 USA
}

\begin{abstract}
Vultures comprise two geographically isolated and taxonomically distinct groups, Old World accipitrids and New World vulturids, and provide a classic case of convergent evolution. In both regions, several species of vultures often feed together in large numbers on carcasses. Behavioral studies of East African and Amazonian vultures have documented parallels in apparent ecological separation within this guild of specialized scavengers. Here morphological differences in skull, beak, and mandibular dimensions are compared among sympatric vultures in East Africa, South Africa, the Indian subcontinent, Amazonia, and the Pleistocene Rancho La Brea deposits in California. A discriminant function analysis based on morphological indices separates three basic feeding types: rippers, gulpers, and scrappers. Vultures of the three feeding types are present in both Pleistocene and Recent assemblages and show a similar distribution of body sizes into three size classes, suggesting that competition has favored similar pathways of ecological separation. This is true even when phylogenetic differences among some of the assemblages are partially accounted for. Comparisons between the fossil and extant New World vultures indicate that more specialized species were prone to extinction and that there has been a reduction in body size since the Pleistocene.
\end{abstract}

Key words: Accipitridae; body size; Cathartidae; feeding indices; guild; Old and New World vultures; Rancho La Brea; scavengers; vultures; Vulturidae.

\section{INTRODUCTION}

Vultures are large birds $(1.5-10 \mathrm{~kg})$ that feed primarily on carrion. They have naked or sparsely feathered heads and relatively strong beaks for tearing flesh, both features related to their scavenging mode of life (Grossman and Hamlet 1964, Brown and Amadon 1968). Vultures are currently represented by two taxonomically distinct groups. Old World vultures are closely related to hawks and eagles (family Accipitridae) (Brown and Amadon 1968), whereas New World vultures show phylogenetic affinities to the ciconiid storks (family Vulturidae, auct. Cathartidae) (Ligon 1967, Rea 1983, Olson 1985, Emslie 1988, Sibley and Ahlquist 1990). These two groups provide a classic case of convergent evolution, in which similarities can be ascribed to functional convergences between the Old and New World species. In some areas such as the Indian subcontinent, Amazonia, South Africa, and East Africa, up to six species of vultures coexist (Grossman and Hamlet 1964, Kruuk 1967, Brown and Amadon 1968). In North America, vulture diversity was comparable during the recent past as evidenced by the abundant remains found at the Pleistocene Rancho La Brea tar pits in California (40000-10000 yr before present). Given the Pleistocene and Recent examples, vulture assemblages can be studied in both space and time.

\footnotetext{
' Manuscript received 11 August 1992; revised 19 July 1993 ; accepted 8 September 1993.
}

Vultures can be considered as comprising an ecological guild, i.e., a group of species that exploits a particular resource in a similar way (Root 1967). Although there are sympatric nonvulture avian scavengers within the aforementioned areas (e.g., ravens, storks, some eagles), only vultures feed almost exclusively on carrion. Wherever vultures are sympatric, competition for available resources is likely to be intensified and differences in behavior, morphology, or both may be expected (Lack 1971). Competition among sympatric vultures is suggested by behavioral studies. Kruuk (1967) studied sympatric Old World vultures in East Africa and found ecological differences based on arrival times at a carcass, aggression, beak size, and body size. Houston (1975) showed further ecological differences based on habitat preferences and flying capabilities. Kruuk (1967) determined three species pairs in East Africa that appear to be in more direct competition with each other than with other vultures based on greater aggression exhibited within each group than among groups. One group contained the two smallest species, Neophron percnopterus and Necrosyrtes monachus, that tend to feed on smaller scraps around a carcass. The second group contained two griffon vulture species, Gyps rueppelli and G. africanus, that tend to feed primarily on the softer muscles and viscera of its prey. The third group contained Torgos tracheliotus and Trigonoceps occipitalis, which feed primarily on the hides and tougher parts of a carcass.

The East African studies by Kruuk (1967) and Houston (1975) determined that sympatric vultures differ in aspects of morphology (body size and beak strength) 
TABLE 1. Species used in the analysis; $N=$ number of specimens; NS, NB, NM = number of fossil specimens of the skull, beaks, and mandible, respectively. Species codes are used in figures.

\begin{tabular}{|c|c|c|c|c|c|c|c|c|}
\hline \multirow[b]{2}{*}{ Species } & & & \multirow[b]{2}{*}{$\mathrm{N}$} & \multirow[b]{2}{*}{$\begin{array}{l}\text { Species } \\
\text { code }\end{array}$} & \multicolumn{3}{|c|}{ Skull shape indices } & \multirow[b]{2}{*}{$\begin{array}{l}\text { Diet } \\
\text { group* }\end{array}$} \\
\hline & & & & & $\begin{array}{c}\text { Beak } \\
(\times 10)\end{array}$ & Skull & Mand & \\
\hline \multicolumn{9}{|l|}{ Amazonia } \\
\hline Vulture gryphus & & & 7 & A & 1.11 & 2.87 & 0.22 & $\cdots$ \\
\hline Gymnogyps californianus & & & 8 & B & 1.19 & 3.00 & 0.21 & $\cdots$ \\
\hline Sarcorhamphus papa & & & 9 & $\mathrm{C}$ & 1.24 & 2.05 & 0.20 & 1 \\
\hline Coragyps atratus & & & 8 & $\mathrm{D}$ & 0.92 & 2.80 & 0.17 & 2 \\
\hline Cathartes melambrotus & & & 4 & $E$ & 0.91 & 2.50 & 0.17 & $\cdots$ \\
\hline C. aura & & & 10 & $\mathrm{~F}$ & 0.95 & 2.45 & 0.16 & 3 \\
\hline C. hurrovianus & & & 5 & G & 0.87 & 2.48 & 0.17 & 3 \\
\hline \multicolumn{9}{|l|}{ East and South Africat } \\
\hline Torgos (Aegvpius) tracheliotus & & & 5 & $\mathbf{J}$ & 1.94 & 1.82 & 0.15 & 1 \\
\hline Trigonoceps (A.) occipitalis & & & 5 & $\mathrm{~K}$ & 1.62 & 1.77 & 0.17 & 1 \\
\hline Gyps rueppelli (only in E. Africa) & & & 2 & M & 1.61 & 2.53 & 0.15 & 2 \\
\hline Gyps coprotheres (only in S. Africa) & & & 3 & $\mathrm{~N}$ & 1.73 & 2.44 & 0.16 & $\cdots$ \\
\hline Gyps africanus & & & 8 & $\mathrm{O}$ & 1.57 & 2.53 & 0.16 & 2 \\
\hline Necrosyrtes monachus & & & 5 & $\mathrm{~S}$ & 0.91 & 2.28 & 0.12 & 3 \\
\hline Neophron percnopterus & & & 4 & $\mathrm{~T}$ & 1.16 & 2.18 & 0.15 & 3 \\
\hline Gupohierax angolensis & & & 6 & $\mathrm{U}$ & 1.68 & 2.24 & 0.16 & $\cdots$ \\
\hline Gypaetus harhatus & & & 4 & $\mathrm{~V}$ & 1.72 & 2.13 & 0.20 & $\cdots$ \\
\hline \multicolumn{9}{|l|}{ India } \\
\hline Aegypius monachus & & & 4 & $\mathrm{H}$ & 1.56 & 1.82 & 0.18 & $\cdots$ \\
\hline Sarcogyps (Aegypius) calva & & & 5 & I & 1.63 & 1.82 & 0.22 & $\cdots$ \\
\hline Glps fullus & & & 4 & $\mathrm{~L}$ & 1.57 & 2.59 & 0.20 & $\cdots$ \\
\hline$G$ hengalensis & & & 2 & $\mathrm{P}$ & 1.56 & 2.48 & 0.22 & $\cdots$ \\
\hline G. himalayensis & & & 1 & Q & 1.62 & 2.47 & 0.15 & $\cdots$ \\
\hline G. indicus & & & 1 & $\mathrm{R}$ & 1.64 & 2.40 & 0.24 & $\cdots$ \\
\hline Neophron percnopterus & & & 4 & $\mathrm{~T}$ & 0.91 & 2.18 & 0.15 & 3 \\
\hline Gypaetus barhatus & & & 4 & $\mathrm{~V}$ & 1.72 & 2.13 & 0.20 & $\cdots$ \\
\hline La Brea & NS & NB & NM & & & & & \\
\hline Breagyps clarkii & 5 & 4 & 1 & $\mathrm{a}$ & 1.27 & 3.39 & 0.18 & $\cdots$ \\
\hline Gymnogyps californianus & 29 & 20 & 8 & $\mathrm{~b}$ & 1.00 & 3.32 & 0.20 & $\cdots$ \\
\hline Coragyps occidentalis & 17 & 9 & 1 & $\mathrm{c}$ & 0.95 & 3.01 & 0.12 & $\cdots$ \\
\hline Cathartes aura & 3 & 3 & 1 & $\mathrm{~d}$ & 0.96 & 2.69 & 0.16 & $\cdots$ \\
\hline Neogyps errans & 3 & 7 & 4 & $\mathrm{e}$ & 1.51 & 1.72 & 0.15 & $\cdots$ \\
\hline Neophrontops americanus & 4 & 8 & 1 & $\mathrm{f}$ & 0.97 & 2.23 & 0.16 & $\ldots$ \\
\hline
\end{tabular}

* Based on Kruuk (1967) and Houston (1988); 1 = rippers, 2 = gulpers, 3 = scrappers (see Methods: Morphology).

$\dagger$ All African species occur in both assemblages except as indicated.

that reflect resource use. This is true to a lesser degree in New World vultures as well (Houston 1988). This suggests that interspecific competition has selected for resource partitioning and thus similar patterns might be observed among vultures in other regions. This study explores whether the three groups observed by Kruuk exist in other regions by quantifying differences in body size and skull morphology among vultures in one fossil and four extant assemblages. Measures of skull, beak, and mandibular morphology were compared with feeding behavior using a principal components analysis and a discriminant function analysis. All vulture species in the Accipitridae and Vulturidae (Table 1) were analyzed, including some African species not studied by Kruuk (1967). He did not consider two vulture species in Africa that are more specialized in their feeding ecology: Gypaetus barbatus, a bone specialist, and $G y$ pohierax angolensis, an oil palm specialist. Overlap in species composition is extensive in the case of the East and South African vultures where all but one species are the same, and two of the eight species in Africa also occur in India (Table 1). The Amazonian and La Brea vultures from the New World are geographically separated and phylogenetically distinct from the Old World species. Thus the evolutionary history of the New and Old World vultures are independent and comparisons between them provide the most robust test of both convergence in phenotype and in patterns of ecological separation within this guild. New World vultures in the Pleistocene Rancholabrean and present day Amazonian assemblages share two species, Gymnogyps californianus and Cathartes aura (Table 1); fossil and extant forms of these two species were analyzed separately to determine differences through time. In Amazonia, G. californianus is not sympatric with the other species but was included as a surrogate for a large condor (Gymnogyps howardae), about the size of $G$. californianus, present during the Pleistocene. Unfortunately, $G$. howardae is not represented by any skull material (Campbell 1979). 

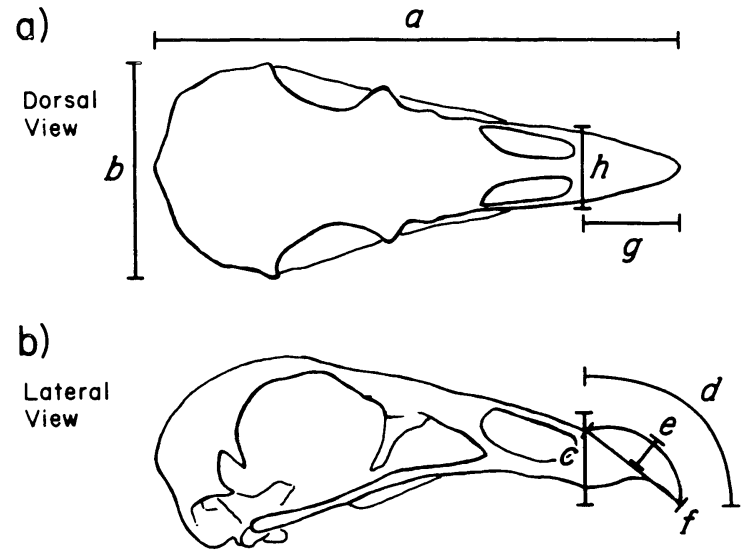

c) Dorsal

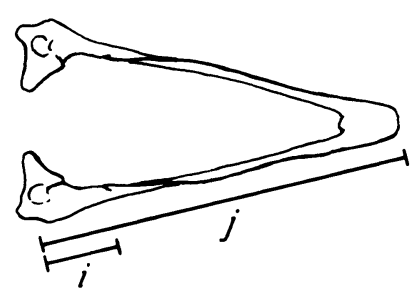

FIG. 1. Measurements used to construct the feeding indices: ( a) skull shape $=(a / h)$; (b) and (a) beak index $=(g / h)$ $\times(c / d) \times(e / f) ;(c)$ mandible showing adductor index $=(i / j)$.

\section{Methods}

\section{Morphology}

The skull was examined as three separate units, the cranium, beak, and mandible, in part, because elements of the skull often preserve as these isolated parts. Thirteen measurements intended to reflect functional differences were made on the various species (Table 2). Measurements were taken with digital calipers in millimetres, and all analyses were done using the SYSTAT statistical package (Wilkinson 1989). Extant specimens studied were housed at: the American Museum of Natural History, New York (AMNH); the U.S. National Museum of Natural History (USNM); the Natural History Museum of Los Angeles County (LACM); the University of California, Berkeley, Museum of Vertebrate Zoology (UCMVZ); San Diego Natural History Museum (SDNH); University of Kansas Museum of Natural History (KUNHM); Louisiana State University Museum of Natural Science (LSUMZ); the British Museum (Natural History) (BMNH); and the University of California, Los Angeles, Bird and Mammal collection (UCLA). Fossil specimens were housed at the University of California, Berkeley, Museum of Vertebrate Paleontology (UCMVP) and the George C. Page Museum in Los Angeles (PAGE).

Three indices (ratios) were constructed to describe the shape of the skull, beak, and mandible, respectively. Skull shape was calculated as total skull length/ skull width (Fig. 1a). Relatively wider skulls provide
TABLE 2. Measurements taken on the skull.

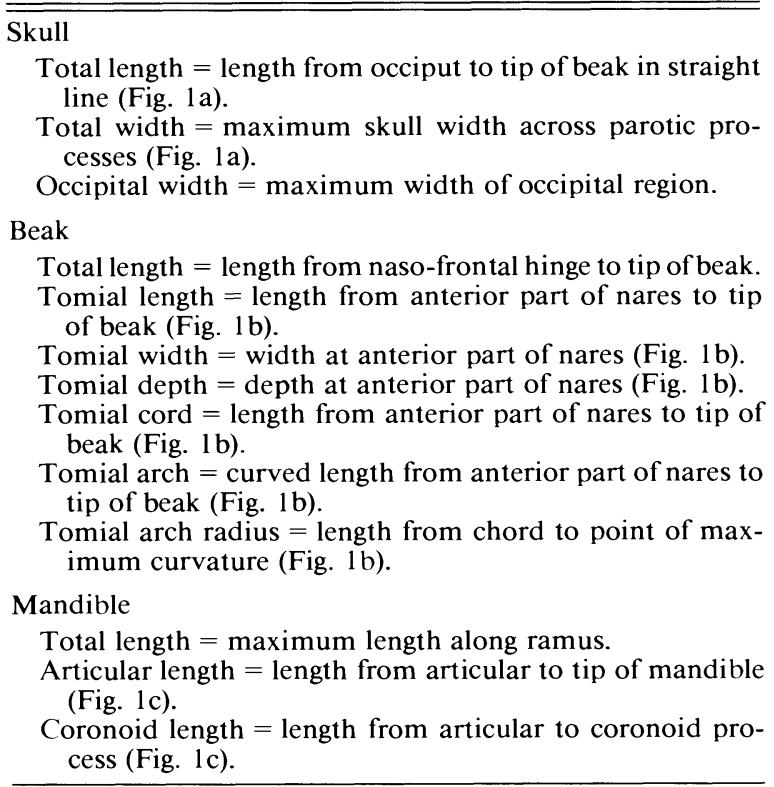

greater moment arms or mechanical advantage for neck muscles that control skull movements and thus probably reflect a greater ability of the skull to twist and consequently rip meat from a carcass. A beak index was constructed that would reflect the relative capability of different beaks for tearing flesh. Because vulture beaks are generally of similar design, extreme differences in any one dimension do not occur and thus a single index was calculated by multiplying three ratios together: (1) relative beak shape (beak length/beak width), (2) relative beak depth (beak depth/beak arc length), and (3) relative beak curvature (beak arc radius/beak chord length) (Fig. lb). This index incorporates the relative sizes of each dimension of the beak; a large value for this index indicates a beak specialized for enhanced tearing ability (e.g., relatively long, deep, and curved). The mandibular or adductor index was calculated as the relative length of the estimated adductor muscle moment arm (distance from the articular to the coronoid process/distance from the articular to the anterior tip of the mandible) (Fig. 1c). A greater value for this index indicates a greater mechanical advantage of the jaw closing muscles. Species means were calculated for each of these indices.

A principal components analysis (PCA) was used as an exploratory tool to display the species according to the combined values of the morphological indices. This analysis summarizes the data as linear combinations of variables or components; each component is orthogonal and independent and accounts for subsequent remaining variation in the data (Morrison 1967, Cooley and Lohnes 1971). The indices were $\log _{10}$ transformed and the PCA was run using a covariance matrix. 
A discriminant function analysis (DFA) was used on the log-transformed indices to assess their ability as predictors of feeding behavior. This analysis calculates linear combinations of variables that maximize the differences among designated groups and indicates the variables (indices) that contribute most to the separation of the groups (Morrison 1967, Cooley and Lohnes 1971). Each vulture species was assigned to one of three feeding groups based primarily on the behavioral data of Kruuk (1967) and Houston (1988): group 1 (rippers) feed primarily on the tough skin and hide of a carcass, group 2 (gulpers) feed primarily on the softer viscera, and group 3 (scrappers) feed primarily on smaller scraps on and around the carcass (Table 1). The DFA also includes a classification phase in which unknowns can be assigned to their most probable group. This allowed the prediction of the feeding behavior/morphology of the extinct La Brea species, the Indian vultures, and the other vultures not studied by Kruuk (1967) or Houston (1975, 1988). Finally, the distribution and diversity of feeding types in all regions were compared in terms of numbers of taxa of each feeding type.

\section{Phylogenetic considerations}

It is generally accepted that Old and New World vultures are not closely related, and phylogenies have been published for New World vulture genera (Emslie 1988) and some Old World vulture genera (Kemp and Crowe 1990). Molecular data confirm that clades of select Old and New World species are not closely related (Sibley and Ahlquist 1990). A nested analysis of variance (ANOVA) was used to test for hierarchical differences at each taxonomic level (family, genus, species) (Harvey and Pagel 1991). To account for the confounding effect of phylogeny and function, the data were then subjected to the autocorrelation analysis described by Gittleman and Kot (1990), which utilizes Moran's (1950) I statistic. This method removes or adjusts for the variation resulting from phylogeny so actual differences presumably can be compared more reasonably. For comparison, the analyses were done using both the original indices and the Moran's $I$ or adjusted indices.

\section{Size distributions}

Body size has been shown to be an important determinant of dominance among vultures at a carcass (Kruuk 1967, Wallace and Temple 1987). Separation in size is examined here based on skull dimensions (Table 2) because only skeletal remains are available for fossil specimens. Mean body masses of extant species were taken from the literature (Brown and Amadon 1968, Brown et al. 1982, Wallace and Temple 1987, Houston 1988) and least squares regressions were used to select the best cranial predictors of body mass.

To examine the distribution of body sizes within and among each assemblage, the body size data were $\log _{10}$ transformed so that body size ratios were constructed
TABLE 3. Results of principal components analysis. Original index: loadings for first two principal components for $\log _{10^{-}}$ transformed indices of covariance matrix with \% variance for each component and eigenvalues. Adjusted index: same as original but using the phylogenetically adjusted statistic (see Methods: Phylogenetic considerations).

\begin{tabular}{lcc}
\hline \hline & I & II \\
\hline Original index & & \\
Beak index & 0.444 & -0.333 \\
Skull shape & -0.241 & 0.528 \\
Mandible or adductor index & 0.972 & 0.283 \\
\% variance & 61 & 24 \\
Eigenvalue & 1.199 & 0.469 \\
Adjusted index & & \\
Beak index & 0.109 & 0.009 \\
Skull shape & -0.052 & 0.044 \\
Mandible or adductor index & 0.021 & 0.064 \\
\% variance & 61 & 24 \\
Eigenvalue & 0.015 & 0.006 \\
\hline
\end{tabular}

as the subtracted differences between species. The differences in body size between successively sized species within each assemblage were analyzed to determine whether the observed ratios were more constant than expected by chance (Barton and David 1956). This probability was expressed as: $\operatorname{Pr}(x<a)=(1 / 2+$ $1 / 2 a)^{-1}$, where $a=b / c, b=$ the smallest segment length or body size ratio, and $c=$ the largest body size ratio. To compare the diversity of size ratios among assemblages, the probability that all observed ratios would exceed a given size ratio was expressed by: $\operatorname{Pr}(x>a)$ $=\left(1-2 a b+a^{2} b^{2}\right)^{n}$, where $a=$ any given size ratio, $b=$ the normalization factor, and $n=$ the total number of ratios (Pielou and Arnason 1966). Both methods are utilized and explained in detail by Simberloff and Boecklen (1981).

\section{RESULTS}

\section{Phylogenetic effects}

A nested ANOVA indicated a significant difference at the family and genus level for the different indices $(P<.05)$, therefore the autocorrelation method presented by Gittleman and Kot (1990) was implemented to adjust for these phylogenetic effects. The correspondence between family membership and morphology can be seen in the PCA (see below); almost all Old World vultures (family Accipitridae) score high $(>0.0)$ on factor 1, whereas most New World vultures (family Vulturidae) score low $(<0.0)$ (Fig. 2A). However, after the original data are transformed using the autocorrelation method, there is considerable overlap between Old and New World species (Fig. 2B).

\section{Functional groups}

The three feeding indices were not highly correlated $(r \leq 0.46)$, indicating that each index probably contributes some unique information to the analysis. The PCA results on the log-transformed indices show factor 1 accounting for $61 \%$ of the variance and the adductor 


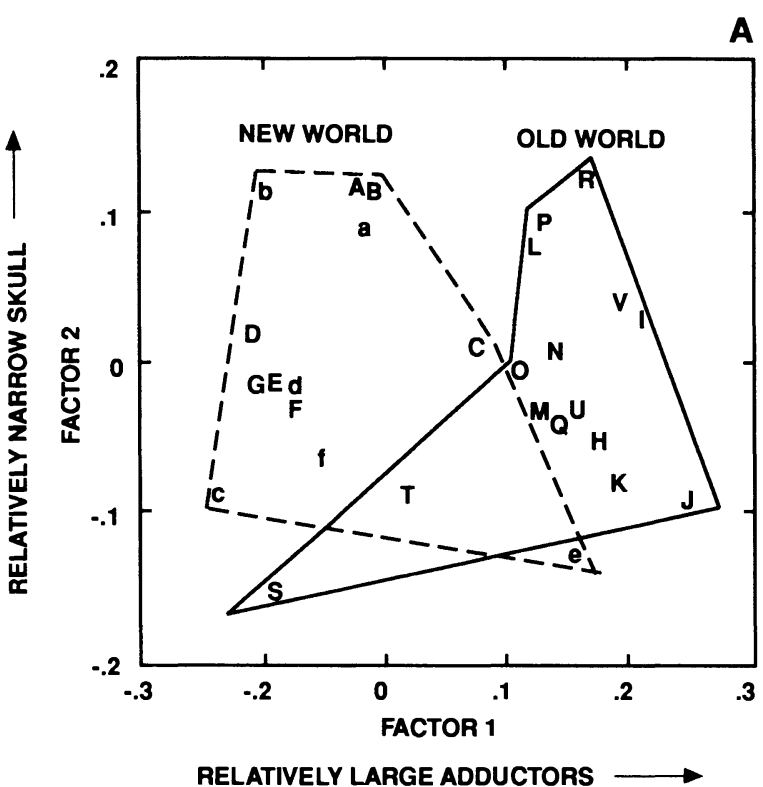

B

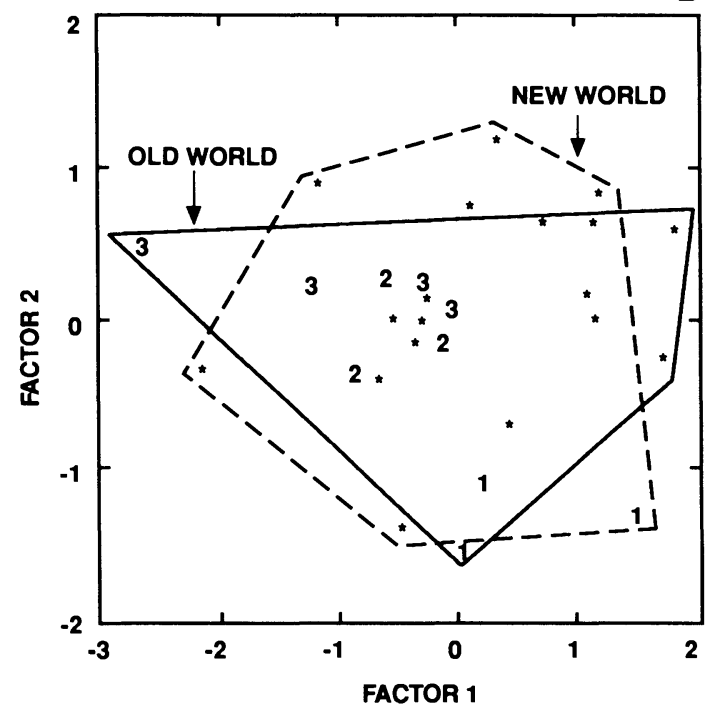

FIG. 2. (A) Principal components analysis for $\log _{10}$-transformed original indices; New World species (-- ) are generally to the left, whereas Old World species (-) are generally to the right; see Table 1 for species codes. (B) Same as (A) but using the phylogenetically adjusted indices (see Methods: Phylogenetic considerations). Note overlap among New and Old World species and poor separation among feeding groups 2 and $3: 1=$ rippers, $2=$ gulpers, $3=$ scrappers, ${ }^{*}=$ species with no a priori assigned behavioral category.

index with the highest loading (Table 3). Factor 2 accounts for $24 \%$ of the variance, with skull shape the highest loaded variable (Table 3 ). Therefore, species with stronger adductors score high on factor 1 (mostly Old World species) and those with narrower skulls score high on factor 2 (New World condors and most Old World griffons) (Table 3; Fig. 2A). When using the
TABLE 4. Results of discriminant function analysis. Original index: coefficients for $\log _{10}$-transformed indices with $\%$ variance for each axis and canonical correlations. Adjusted index: same as original but using the phylogenetically adjusted statistic.

\begin{tabular}{lcc}
\hline & I & II \\
\hline Original index & & \\
Beak index & 1.343 & 0.106 \\
Skull shape & 0.944 & 0.996 \\
Mandible or adductor index & 0.299 & -0.746 \\
\% variance & 75 & 25 \\
Canonical correlations & 0.86 & 0.65 \\
Adjusted index & & \\
Beak index & 0.818 & 0.536 \\
Skull shape & -0.264 & 1.007 \\
Mandible or adductor index & 0.271 & 0.057 \\
\% variance & 75 & 25 \\
Canonical correlations & 0.82 & 0.66 \\
\hline
\end{tabular}

phylogenetically adjusted indices, however, the percent variances accounted by each factor are approximately equal but the beak index has the highest loading on factor 1 and the adductor index has the highest loading on factor 2, followed by skull shape (Table 3). Therefore species with stronger beaks score high on factor 1 (rippers) and those with narrower skulls and relatively longer (stronger) adductors score high on factor 2 (gulpers and scrappers) (Table 4; Fig. 2B). The PCA does not clearly distinguish between the group 2 gulpers and the group 3 scrappers.

The results of the DFA were similar using the original and the adjusted indices so only those using the adjusted data are depicted. As might be expected, the separation of the three groups was much clearer using the DFA than the PCA. The first axis accounts for $75 \%$ of the variance with beak index the highest loaded variable and the second axis accounts for $25 \%$ of the variance with skull shape the highest loaded variable (Table 4). Species with the strongest beaks score high on axis one (group 1 rippers) and those with narrow skulls score high on axis two (group 2 gulpers) (Table 4; Fig. 3A). Therefore, group 1 rippers show the strongest beaks and widest skulls, group 2 gulpers show intermediate beak strength and the narrowest skulls, and group 3 scrappers show the weakest beaks and somewhat narrow skulls (Fig. 3A).

Of the species with known or assigned feeding behaviors, all but two plotted with a high probability $(>0.90)$ within their assigned group. The two exceptions were Cathartes aura and Coragyps atratus. Cathartes aura plotted as a scrapper but only with a probability of 0.51 ( $P=.33$ as a group 2 gulper) (Fig. 3A: F). Coragyps atratus was assigned a priori as a group 2 gulper based on Houston's (1988) observations but was predicted as a group 3 scrapper $(P=.84)$ (Fig. 3A: D).

\section{Assignment of unknowns}

The species classified as unknowns were assigned to one of three feeding classes by the DFA with a prob- 
TABLE 5. Comparisons of body size ratios: Barton-David probability values of similar intra-assemblage body size ratios (Barton and David 1956); and Pielou-Arnason probability values of similar interassemblage body size ratios (Pielou and Arnason 1966).

\begin{tabular}{lcc}
\hline \hline & Barton-David & Pielou-Arnason \\
\hline Amazonia & .049 & $<.001$ \\
East Africa & .049 & $<.001$ \\
South Africa & .037 & $<.001$ \\
India & .023 & $<.001$ \\
La Brea & .019 & $<.001$ \\
\hline
\end{tabular}

ability of group membership. As might be expected, all Old World griffon vulture species from India (Gyps spp.) were predicted as group 2 gulpers like their African congeners (Fig. 3A: L-R). The probabilities were relatively high $(P>.86)$ for all except Gyps indicus $(P$ $=.65$ ), which is represented by only one specimen (Fig. 3A: R). Sarcogvps calva and Aegypius monachus from India were predicted as group 1 rippers with high probabilities $(P>.91)$ (Fig. 3A: H, I). Both specialized vultures (Gypaetus barbatus and Gypohierax angolensis) not considered by Kruuk (1967) were predicted as group 2 gulpers ( $P=.81$ and .96 , respectively) (Fig. $3 \mathrm{~A}: \mathrm{V}, \mathrm{U})$. Of the New World vultures, the one species of Cathartes not investigated by Houston (1988) was predicted as a group 3 scrapper $(P=.71)$ (Fig. 3A: E). The fossil and extant New World condors were predicted as group 2 gulpers $(.52<P<.99)$ (Fig. 3A: A, $\mathrm{B}, \mathrm{a}, \mathrm{b})$. Of the remaining fossil vultures from La Brea, Neogyps errans was predicted as a group 1 ripper $(P=$ .94) (Fig. 3A: e), Cathartes aura was predicted as a group 2 gulper $(P=.63)$ (Fig. 3A: d), and Coragyps occidentalis and Neophrontops americanus were predicted as group 3 scrappers $(P=.81$ and .99 , respectively) (Fig. 3A: c, f).

\section{Distribution of functional types}

The number of species within each region ranges from six to eight. Examination of the distribution of species within each region indicates that each contains at least one species of each feeding morphology but the numbers of feeding types within each assemblage are not constant (Fig. 3B). The Old World assemblages are similar in the distribution of species within feeding classes; gulpers predominate over rippers and scrappers (Fig. 4). La Brea also shows a predominance of gulpers but differs from the Old World assemblages by having only one ripper and more scrappers (Fig. 4). Amazonia is the most distinctive in that unlike the Old World assemblages, the scrappers outnumber the other two categories (Fig. 4).

\section{Size distributions}

Of all the variables used to construct the indices (Table 2), skull length was the best predictor of body mass $\left(R^{2}=0.90\right)$ and was therefore used to depict the distribution of body sizes. In each assemblage, species
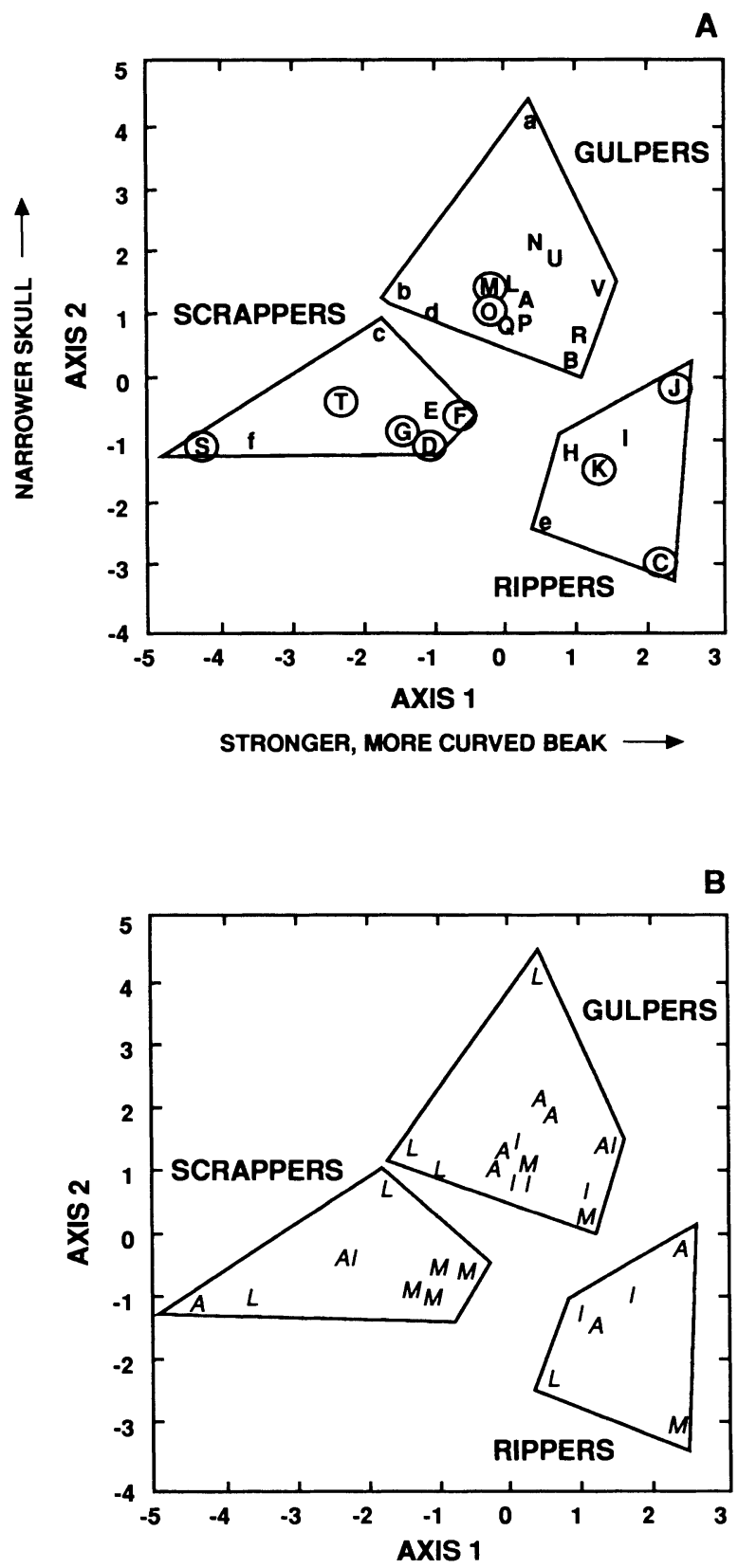

FIG. 3. (A) Discriminant function analysis for species based on phylogenetically adjusted indices; circled letters indicate species assigned a priori to their feeding behavior, except D, which was assigned to group $2 ;-$ _— surround assigned feeding behaviors; see Table 1 for species codes. (B) Same as (A) but with species coded as to their geographic region: $A=$ Africa, $I=$ India, $M=$ Amazonia, $L=\mathrm{La}$ Brea, $A I=$ Africa and India.

tend to be distributed among three size classes (Fig. 5), although this is least apparent in Amazonia. Among assemblages, this distribution of species is more similar than expected by chance (Table 5: $P<.001$ for all assemblages). Within each assemblage, the size ratios between species were neither constant nor randomly 

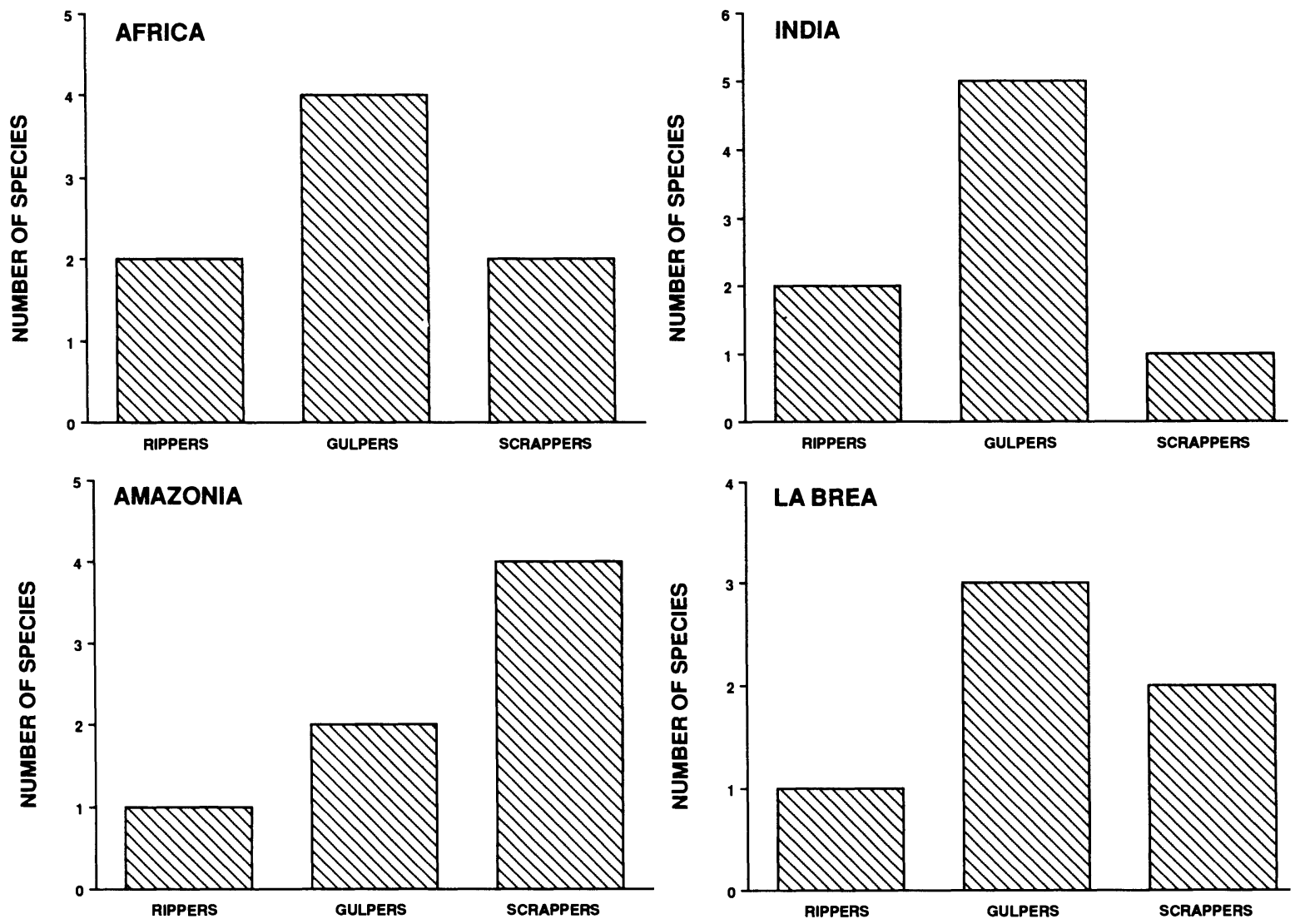

FIG. 4. Number of species of each feeding type for each assemblage.

distributed (Table 5: $P<.05$ for all assemblages) reflecting the distribution of taxa into size classes. All three feeding indices were poorly correlated with size in vultures $\left(R^{2}=0.01,0.39\right.$, and 0.11 for skull shape, beak index, and adductor index, respectively), and this is reflected by the fact that each size class usually includes vultures of different feeding habits (Fig. 5). For example, each of the three size classes in Africa contains more than one feeding type, as do two of the three size classes in India and La Brea, and one of the three in Amazonia (Fig. 5).

\section{DisCUSSION}

It has recently been argued that a phylogenetic analysis is essential when making functional comparisons across taxa (e.g., Cheverud et al. 1985, Gittleman and Kott 1990, Harvey and Pagel 1991). The PCA on the original data indicates strong differences between Old and New World vultures such that Old World species tend to have stronger adductors (Table 3; Fig. 2A). This might reflect real differences in feeding behavior or it simply might reflect a different ancestry. For example, preliminary observations of videos of feeding vultures indicate that some New World condors feed with a scissor-like slicing motion rather than the twist- ing and ripping behavior that is typical of some Old World species; perhaps this behavioral difference is somehow correlated with the taxonomic disparity in adductor strengths. Clearly more quantitative behavioral data are needed to support these observations. However, because the purpose of this paper was to establish the extent of functional similarities among all vultures, the Moran's I correction statistic was implemented as described by Gittleman and Kot (1990) to remove some of the variance resulting from ancestry. This resolved the previous separation between the Old and New World vultures (Fig. 2B). Both the original and adjusted indices were used in the DFA and produced similar separation among the three feeding morphologies.

The DFA separated three feeding morphologies fairly clearly; group 1 rippers have the widest skulls and strongest beaks, group 2 gulpers have the narrowest skulls and intermediate beak strength, and group 3 scrappers have the weakest beaks and narrow skulls. As mentioned previously, wider skulls provide a greater mechanical advantage for neck muscles moving the skull to twist and rip flesh from a carcass, thus reflecting group 1 species' preference for tougher parts of a carcass (Table 1; Fig. 3A: C, J, K). Vultures with the weakest beaks, such as the Old World Neophron perc- 

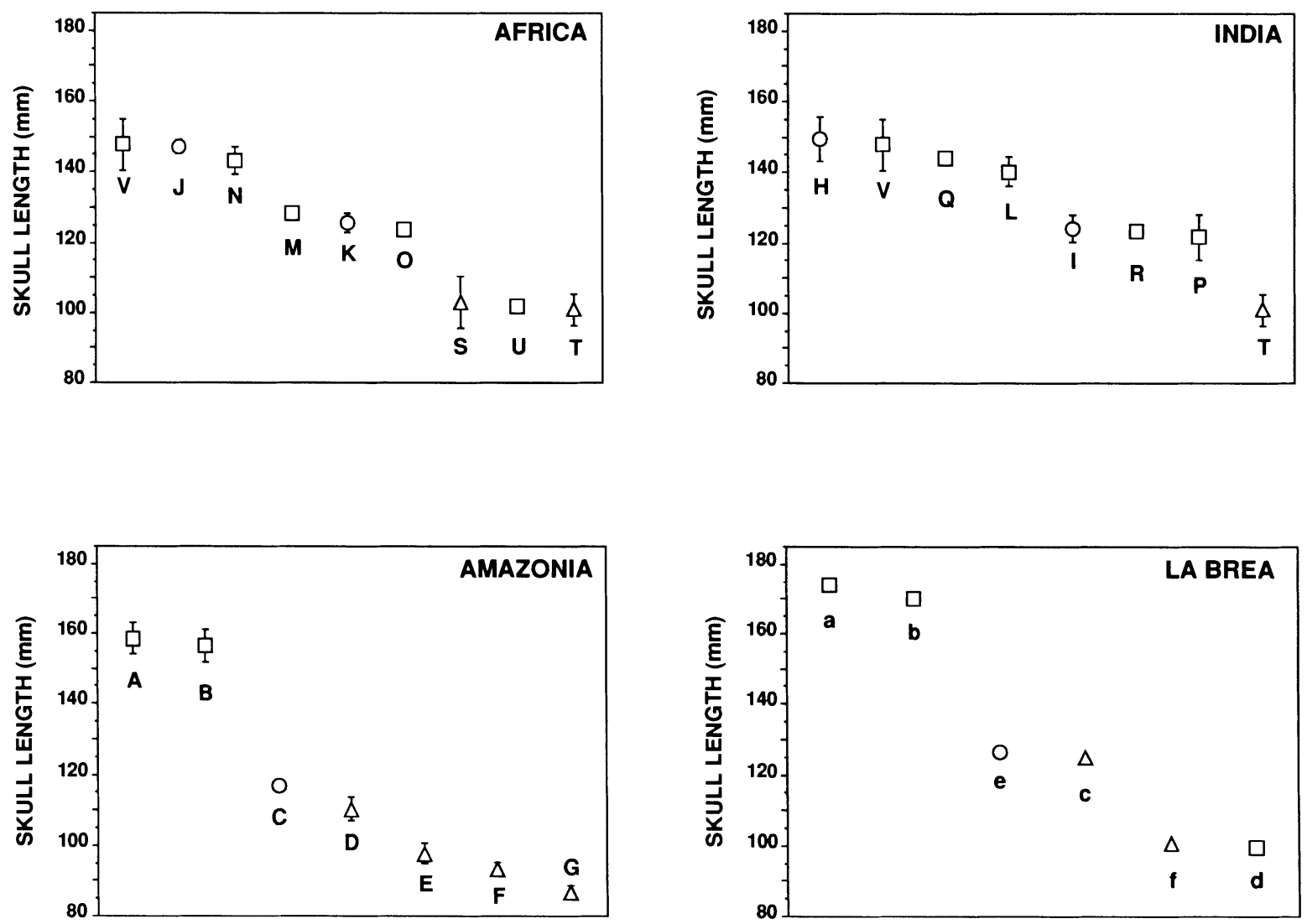

FIG. 5. Size distributions (based on skull length) of species within each assemblage showing means and $95 \%$ confidence intervals; $\bigcirc$ group 1, rippers; $\square$ group 2, gulpers; $\triangle$ group 3, scrappers. Note relative independence of feeding type and body size; see Table 1 for species codes.

nopterus and the New World Cathartes aura, tend to feed on scraps on and around a carcass and are typical of group 3 scrappers (Table 1; Fig. 3A: F, G, S, T). Group 2 gulpers, such as the griffons Gyps rueppelli and $G$. africanus, are intermediate in beak strength but have narrow skulls; they prefer the softer viscera of their prey and often plunge their long necks and narrow skulls deep into carcasses (Table 1; Fig. 3A: M, O). Notably in East Africa, vultures within each of the three species pairs determined by Kruuk (1967) appear to compete more intensely with each other than with other vultures. Based on this study, members of each pair share similar feeding morphologies and are fairly close in the discriminant space (Fig. 3A: $\mathrm{J}$ and $\mathrm{K}, \mathrm{M}$ and $\mathrm{O}$, $\mathrm{S}$ and T). In South Africa, G. rueppelli is "replaced" by $G$. coprotheres, a somewhat larger species. Here, these two griffons, G. africanus and G. coprotheres are again similar (Fig. 3A: N, O). It appears, then, that proximity of species within the discriminant space does reflect somewhat the intensity of competitive interactions observed by Kruuk (1967).

Kruuk did not consider the two remaining vulture species in the African assemblages that are more specialized in their feeding ecology: Gypaetus barbatus and Gypohierax angolensis (Fig. 3A: U, V). Gypohierax angolensis (U) is somewhat problematic because it is the only vulture known to feed predominantly on vegetation, an oil palm (Elaeis guineensis), rather than on carrion. Gypaetus barbatus (V) is more specialized for feeding on bones, often dropping them onto rocks from the air (Brown and Amadon 1968). Both species were predicted as group 2 gulpers. This appears reasonable given that swallowing bones or eating soft oil palms probably does not require very strong beaks nor great ripping actions (wide skulls), and these foods might not always consist of small scraps. It might also reflect a closer ancestry with griffon vultures than with the other Old World species.

Relative to the African vultures, less is known regarding the behavioral ecology of the Indian species, and therefore they were not assigned a priori to a feeding group. Aegypius monachus, the largest vulture, and Sarcogyps calva, an intermediate-sized vulture share close proximity in the discriminant space (Fig. 3A: H, I) and were predicted as group 1 rippers. They have been compared behaviorally to the two African group 1 rippers (Brown and Amadon 1968) and all four may in fact be congeners of Aegypius (Brown et al. 1982). Of the four species of griffon vultures in this region, two occur in the large size class and two in the inter- 
mediate size class. They occupy similar positions within their predicted group 2 (Fig. 3A: L, P, Q, R). More rigorous studies like those on the African species are needed to observe interspecific behaviors at a carcass to determine if indeed there are similar competitive interactions among these Indian vultures.

Houston (1988) observed parallels in the feeding preferences between the East African and Amazonian species and his observations were used to assign them to groups in this study. According to Houston (1988), Sarcorhamphus papa tended to feed predominantly on skin and tendons like Torgos tracheliotus and Trigonoceps occipitalis (group 1 rippers); Cathartes aura and $C$. hurrovianus fed more on scraps on and around a carcass like Neophron percnopterus and Necrosyrtes monachus (group 3 scrappers); and Coragyps atratus fed on softer viscera like Gyps spp. (group 2 gulpers). Interestingly, $C$. atratus was predicted by the DFA as a group 3 scrapper (Fig. 3A: D), even though Houston (1988) described it as similar to the African group 2 gulpers in its behavior. His assignment was based primarily on the fact that it uses its feet to hold the carcass when feeding rather than on its beak and skull morphology. The intermediate-sized Sarcorhamphus papa has a wider skull and slightly stronger beak than other New World vultures (Fig. 3A: C). Other vultures have been observed to wait at an unopened carcass and not feed until S. papa arrived to tear it open (Eitnear 1982). The two extant condors (Vultur gryphus and Gymnogyps californianus) were predicted as group 2 gulpers (Fig. 3A: A, B) although $G$. californianus is assigned with a low probability $(P=.52)$. Its next most likely classification was as a ripper $(P=.48)$, reflecting its stronger beak and wider skull than other gulpers. The fossil $G$. californianus was predicted as a group 2 gulper with a greater probability $(P=.78)$ (Fig. $3 \mathrm{~A}$ : $\mathrm{b}$ to $\mathrm{B})$. Perhaps selection favored this species becoming more of a ripper in the absence of other large sympatric vultures since the Pleistocene. Gymnogyps californian$u s$ is not currently sympatric with any group 1 rippers as it was during the Pleistocene at Rancho La Brea.

Of special interest are the extinct vultures, which provide insights into guild structure prior to the Late Pleistocene extinction. Some of these fossil vultures from La Brea appear to fall in between groups. The two large condors from La Brea, Gymnogyps californianus and Breagyps clarkii, as well as Cathartes aura, were predicted as group 2 gulpers. Although its probability of assignment is high $(P=.99), B$. clarkii is the most deviant member of group 2 with a very narrow skull and long beak (Fig. 3A: a). The Pleistocene representative of $C$. aura was predicted as a group 2 gulper $(P=.81)$, whereas the living form is a group 3 scrapper $(P=.51)$ but more intermediate between the two groups (Fig. 3A: d vs. F). This suggests a shift away from a dependence on large prey in response to the great decline of large herbivores in the New World since the Late Pleistocene (Steadman and Martin 1984, Webb
1984). Such a shift in the prey base may have selected for better scrapping behavior, which appears to be successful for smaller prey; the living $C$. aura is the most widespread and abundant New World vulture. Coragyps occidentalis was a larger version of the living $C$. atratus and both were predicted as group 3 scrappers (Fig. 3A: c, D). The lower probabilities for group membership of some of the fossils and their intermediate positions in the discriminant space suggest that at least half of the vultures from La Brea differed somewhat from modern forms in their feeding behaviors; they were more intermediate between group 2 and 3 feeding morphologies (Fig. 3A: b, c, d). Those vultures that survived the Pleistocene extinction were, according to this analysis, more intermediate in their feeding behavior (Fig. 3A: b, c, d), whereas those with more extreme morphologies went extinct (Fig. 3A: a, e, f). The extinction of more specialized forms during the Late Pleistocene has been shown to be true for both carnivorous birds and mammals (Van Valkenburgh and Hertel, in press).

It appears that wherever vultures occur in a high diversity, they generally show a similar array of feeding morphologies such that there is at least one species in each assemblage exhibiting each of the three feeding behaviors (Fig. 3B). This is true even though there are phylogenetic differences, and geographic and temporal separation among assemblages. After adjusting for variations resulting from phylogeny, sympatric species tend to separate along similar lines and the morphological convergence among these birds based on the selected characters is similar among the different assemblages. This seems to indicate that competition has been an important determinant of feeding morphology among these birds, not surprising for an animal on such a high trophic level. Other workers have found similar evidence of morphological divergence among sympatric carnivorous mammals (Van Valkenburgh 1985, 1988, Sunquist and Sunquist 1989) and some raptors (Schoener 1984).

Of notable interest is the observation that vultures within each assemblage generally tend to cluster into three size classes (Fig. 5) rather than segregate evenly as has been observed in some assemblages of mammalian carnivores (Kiltie 1984, 1988, Dayan et al. $1989 a, b, 1990)$. Schoener (1984) found body size differences among certain raptors to be less in the tropics than in temperate zones suggesting a greater clumping of body sizes in the tropics. This appears to be the case with vultures as well; there is a greater difference among the three size classes at La Brea (temperate) than in the extant more tropical assemblages (Fig. 5).

The three successful feeding strategies on which vultures have converged do not correspond perfectly with body size. The feeding types are scattered among the three size classes with a few exceptions; there are no large scrappers, no small rippers, and there is a tendency for the smallest species to be scrappers (La Brea 
and Amazonia each contain one intermediate-sized scrapper). This pattern of similar-sized birds differing in feeding type further suggests that competition is an important determinant of vulture feeding morphology. It would be interesting to determine whether the three sizes reflect aerodynamic constraints rather than feeding constraints given that skull size is unlikely to have evolved in isolation from the rest of the body. Most vultures excel at static soaring behavior, on which they rely to locate their greatly dispersed food (Pennycuick 1972). In addition, it is probable that sympatric species within size classes exhibit more habitat segregation than those of different sizes. This has been demonstrated somewhat for African vultures (Houston 1975) and New World vultures (Houston 1988, Hertel 1992). More work on the postcranial anatomy should help resolve these issues (F. Hertel, unpublished manuscript).

Although there are three similar size classes in all assemblages, vultures from La Brea are slightly larger in body size (Fig. 5). The fossil specimens of Gymnogyps californianus and Cathartes aura were both larger than the modern forms and Coragyps occidentalis was a larger version of the living C. atratus (Fig. 5). A reduction in body size since the Pleistocene has also been documented in mammals (Kurtén and Anderson 1983) and vultures (Fisher 1944, Hertel 1992) and appears to be correlated with warmer climates and less availability of resources (Graham and Lundelius 1984, Guilday 1984). As stated previously, the severe decline in the diversity of large hevbivores in the latest Pleistocene probably favored size reduction in the large scavenging vultures.

The La Brea assemblage had fewer vulture species compared with the other assemblages (Fig. 4). Perhaps the abundance of large prey at La Brea facilitated facultative scavenging by the numerous raptors found there, which would presumably have been group 1 rippers. The most abundant bird found at Rancho La Brea is the Golden Eagle (Aquila chrysaetus), a noted facultative scavenger. The greater number of group 2 gulpers in the Old World (Fig. 4) is partly a result of the two dietary specialists (Gypohierax angolensis and $G y$ paetus barbatus), which probably have limited competitive interactions with other vultures as a result of their prey preference. Without these two species the number of species within each feeding category is fairly similar among all except the Amazonian assemblage (Fig. 4). The dominance of relatively small scrappers in Amazonia (Fig. 4) probably reflects the abundance of small prey and limited large prey in the New World tropical forests compared to the other regions (Houston 1985). Selection for smaller body size in forested areas is expected (Brown and Amadon 1968, Houston 1985) and the presence of Cathartes melambrotus and $C$. burrovianus appears to be a recent event; they have not been found in the Pleistocene Talara tar seep deposits in Peru despite the presence of numerous other bird species (Campbell 1979).

\section{Conclusions}

1) Three feeding types can be distinguished among vultures based on skull, beak, and mandibular measurements; rippers tend to feed on tougher carcass parts, gulpers on softer viscera, and scrappers on smaller scraps.

2) New World vultures as a group tend to have weaker beaks, stronger adductors, and narrower skulls than do Old World vultures, probably reflecting both differences in function and in ancestry.

3) Based on behavioral observations of interactions at a carcass, competition appears most intense between certain species, which in this functional analysis tend to show similar morphological adaptations for feeding.

4) Within each assemblage, body sizes of vultures tend to cluster into three size classes rather than segregate evenly along a size gradient.

5) Despite differences in ancestry between New and Old World vultures, each assemblage includes species from each of the three feeding types: rippers, gulpers, and scrappers. Most often each size class includes species of at least two feeding types, suggesting competition is an important determinant of vulture feeding morphology.

\section{ACKNOWLEDGMENTS}

I wish to thank: W. Anyonge, D. Buth, E. Geffen, T. Rasmussen, and especially B. Van Valkenburgh for improving this paper; J. Gittleman for the phylogenetic adjustment statistics; B. Obst for his help and encouragement in the early stages of this work; S. Olson (USNM), Mary La Croy (AMNH), T. Demere (SDNH), J. V. Remsen (LSUMZ), H. Hutchison (UCMVP), D. Sakurai (UCMVZ), K. Campbell (LACM), B. Chandler (KUNHM), P. Colston (BMNH), G. Jefferson, E. Scott, and C. Shaw (Page), and J. Northern (UCLA) for their curatorial assistance. This work was funded in part by Sigma $\mathrm{Xi}$ and a Frank Chapman Grant from the American Museum of Natural History.

\section{Literature Cited}

Barton, D. E., and F. N. David. 1956. Some notes on ordered random intervals. Journal of the Royal Statistical Society (Series B) 18:79-94.

Brown, L., and D. Amadon. 1968. Eagles, hawks, and falcons of the world. McGraw-Hill, New York, New York, USA.

Brown, L., E. Urban, and K. Newman. 1982. The birds of Africa. Volume 1. Academic Press, New York, New York, USA.

Campbell, K. 1979. The non-passerine Pleistocene avifauna of the Talara tar seeps, northwestern Peru. Royal Ontario Museum, Life Sciences Contribution 118:1-203.

Cheverud, J. M., M. M. Dow, and W. Leutenegger. 1985. The quantitative assessment of phylogenetic constraints in comparative analyses: sexual dimorphism in body weights among primates. Evolution 39:1335-1351.

Cooley, W. W., and P. R. Lohnes. 1971. Multivariate data analysis. Wiley, New York, New York, USA.

Dayan, T., D. Simberloff, E. Tchernov, and Y. Yom-Tov. 1989a. Inter- and intraspecific character displacement in mustelids. Ecology 70:1526-1539.

Dayan, T., D. Simberloff, E. Tchernov, and Y. Yom-Tov. 1990. Feline canines: community-wide character displacement among the small cats of Israel. American Naturalist 136:39-60. 
Dayan, T., E. Tchernov, Y. Yom-Tov, and D. Simberloff. 1989b. Ecological character displacement in Saharo-Arabian Vulpes: outfoxing Bergman's rule. Oikos 55:263-272.

Eitnear, J. C. 1982. King Vulture-the only true rain forest vulture. American Federation of Aviculture Watchbird 9: 48-49.

Emslie, S. 1988. The fossil history and phylogenetic relationships of condors (Ciconiiformes: Vulturidae) in the New World. Journal of Vertebrate Paleontology 8:212-228.

Fisher, H. I. 1944. The skulls of cathartid vultures. Condor 46:272-296.

Gittleman, J. L., and M. Kot. 1990. Adaptation: statistics and a null model for estimating phylogenetic effects. Systematic Zoology 39:227-243.

Graham, R. W., and E. L. Lundelius. 1984. Coevolutionary disequilibrium and Pleistocene extinctions. Pages 223-249 in P. Martin and R. Klein, editors. Quaternary extinctions. University of Arizona Press, Tucson, Arizona, USA.

Grossman, M. L., and J. Hamlet. 1964. Birds of prey of the world. Bonanza, New York, New York, USA.

Guilday, J. E. 1984. Pleistocene extinction and environmental change: a case study of the Appalachians. Pages 250258 in P. Martin and R. Klein, editors. Quaternary extinctions. University of Arizona Press, Tucson, Arizona, USA.

Harvey, P., and M. Pagel. 1991. The comparative method in evolutionary biology. Oxford University Press, New York, New York, USA.

Hertel, F. 1992. Morphological diversity of past and present New World vultures. Pages 413-418 in K. E. Campbell, Jr., editor. Papers in Avian Paleontology Honoring Pierce Brodkorb, Los Angeles County Museum Science Series, Number 36.

Houston, D. C. 1975. Ecological isolation of African scavenging birds. Ardea 63:55-64.

. 1985. Evolutionary ecology of afrotropical and neotropical vultures in forests. Pages 856-864 in P. Buckley, M. Foster, E. Morton, R. Ridgley, and F. Buckley, editors. Neotropical ornithology. American Ornithologists' Union, Ornithological Monographs, Number 36.

- 1988. Competition for food between neotropical vultures in forests. Ibis 130:402-417.

Kemp, A. C., and T. M. Crowe. 1990. A preliminary phylogenetic and biogeographic analysis of the genera of diurnal raptors. Pages 161-175 in G. Peters and R. Hutterer, editors. Vertebrates in the Tropics. Proceedings of the International Symposium on Vertebrate Biogeography and Systematics in the Tropics. Alexander Koenig Zoological Research Institute of Zoology Museum, Bonn, Germany.

Kiltie, R. A. 1984. Size ratios among sympatric neotropical cats. Oecologia 61:41 1-416.

- 1988. Interspecific size regularities in tropical felid assemblages. Oecologia 76:97-105.

Kruuk, H. 1967. Competition for food between vultures of East Africa. Ardea 55:171-193.

Kurtén, B., and E. Anderson. 1980. Pleistocene mammals of North America. Columbia University Press, New York, New York, USA.

Lack, D. 1971. Ecological isolation in birds. Harvard University Press, Cambridge, Massachusetts, USA.
Ligon, D. 1967. Relationships of cathartid vultures. Occasional Papers, Museum of Zoology, University of Michigan 651:1-26.

Moran, P. A. 1950. Notes on continuous stochastic phenomena. Biometrika 37:17-23.

Morrison, D. F. 1967. Multivariate statistical methods. McGraw-Hill, New York, New York, USA.

Olson, S. 1985. The fossil record of birds. Pages 79-256 in D. S. Farner and J. R. King, editors. Avian biology. Volume 8. Academic Press, Orlando, Florida, USA.

Pennycuick, C. J. 1972. Soaring behavior and performance of some East African birds observed from a motor glider. Ibis 114: 178-218.

Pielou, E. C., and A. N. Arnason. 1966. Correction to one of MacArthur's species-abundance formulas. Science 203: 470-471.

Rea, A. 1983. Cathartid affinities: a brief overview. Pages 3-25 in S. Wilbur and J. Jackson, editors. Vulture biology and management. University of California Press, Los Angeles, California, USA.

Root, R. 1967. The niche exploitation of the blue-gray gnatcatcher. Ecological Monographs 37:317-350.

Schoener, T. 1984. Size differences among sympatric, birdeating hawks: a worldwide survey. Pages 254-281 in D. Strong, D. Simberloff, L. Abele, and A. Thistle, editors. Ecological communities: conceptual issues and the evidence. Princeton University Press, Princeton, New Jersey, USA.

Sibley, C. G., and J. E. Ahlquist. 1990. Phylogeny and classification of birds: a study in molecular evolution. Yale University Press, New Haven, Connecticut, USA.

Simberloff, D., and W. Boecklen. 1981. Santa Rosalia reconsidered: size ratios and competition. Evolution 35: $1206-$ 1228.

Steadman, D. W., and P. S. Martin. 1984. Extinction of birds in the Late Pleistocene of North America. Pages 466477 in P. Martin and R. Klein, editors. Quaternary extinctions. University of Arizona Press, Tucson, Arizona, USA.

Sunquist, M. E., and F. C. Sunquist. 1989. Ecological constraints on predation by large felids. Pages 283-30l in J. Gittleman, editor. Carnivore behavior, ecology, and evolution. Cornell University Press, Ithaca, New York, USA.

Van Valkenburgh, B. 1985. Locomotor diversity in past and present guilds of large predatory mammals. Paleobiology 11:406-428.

11. 1988. Trophic diversity in past and present guilds of large predatory mammals. Paleobiology 14:155-173.

Van Valkenburgh, B., and F. Hertel. 1994. The decline of North American predators during the Late Pleistocene. Illinois State Museum of Scientific Papers, in press.

Wallace, M., and S. Temple. 1987. Competitive interaction within and between species in a guild of avian scavengers. Auk 104:290-295.

Webb, D. 1984. Ten million years of mammal extinctions in North America. Pages 189-210 in P. Martin and R. Klein, editors. Quaternary extinctions. University of Arizona Press, Tucson, Arizona, USA.

Wilkinson, L. 1989. SYSTAT: the system for statistics. SYSTAT, Evanston, Illinois, USA. 